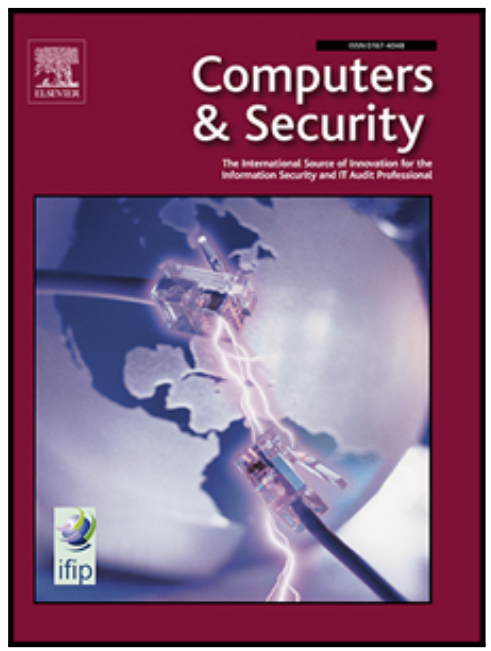

Cyber-security: Identity Deception Detection on Social Media Platforms

Estee van der Walt, J.H.P. Eloff, Jacomine Grobler

PII: S0167-4048(18)30650-3

DOI: 10.1016/j.cose.2018.05.015

Reference: COSE 1352

To appear in:

Computers \& Security

Received date:

17 January 2018

Revised date:

11 April 2018

Accepted date:

31 May 2018

Please cite this article as: Estee van der Walt, J.H.P. Eloff, Jacomine Grobler, Cyber-security: Identity Deception Detection on Social Media Platforms, Computers \& Security (2018), doi: 10.1016/j.cose.2018.05.015

This is a PDF file of an unedited manuscript that has been accepted for publication. As a service to our customers we are providing this early version of the manuscript. The manuscript will undergo copyediting, typesetting, and review of the resulting proof before it is published in its final form. Please note that during the production process errors may be discovered which could affect the content, and all legal disclaimers that apply to the journal pertain. 


\section{Cyber-security: Identity Deception Detection on Social Media Platforms}

\author{
Estee van der Walt \\ Department of Computer Science \\ University of Pretoria, South Africa \\ estee.vanderwalt@gmail.com
}

\author{
J.H.P. Eloff \\ Department of Computer Science \\ University of Pretoria, South Africa \\ eloff@cs.up.ac.za
}

\author{
Jacomine Grobler \\ Dept. of Industrial and Systems Eng. \\ University of Pretoria, South Africa \\ jacomine.grobler@up.ac.za
}

\begin{abstract}
Social media platforms allow billions of individuals to share their thoughts, likes and dislikes in real-time, without any censorship. This freedom, however, comes at a cyber-security risk. Cyber threats are more difficult to detect in a cyber world where anonymity and false identities are ever-present. The speed at which these deceptive identities evolve calls for solutions to detect identity deception. Cybersecurity threats caused by humans on social media platforms are widespread and warrant attention. This research posits a solution towards the intelligent detection of deceptive identities contrived by human individuals on social media platforms (SMPs). Firstly, this research evaluates machine learning models by using attributes such as the "profile image" found on SMPs. To improve on the results delivered by these models, past research findings from the field of psychology, such as that humans lie about their gender, are used. Newly engineered features such as "gender-derived-from-the-profileimage" are evaluated to grasp whether these features detect deception with greater accuracy. Furthermore, research results from detecting non-human (also known as bot) accounts are also leveraged to improve on the initial results. These machine learning results are lastly applied to a proposed model for the intelligent detection and interpretation of identity deception on SMPs. This paper shows that the cyber-security threat of identity deception can potentially be minimized, should the vulnerability in the current way of setting up user accounts on SMPs be re-engineered in the future.
\end{abstract}

Keywords: cyber-security, identity deception, social media, big data, bots, grooming

\section{INTRODUCTION}

Nowadays, the cyber-security media are very concerned about people being exposed to all sorts of abuse on Social Media Platforms (SMPs). The malicious intent of humans deceiving other humans constitutes a cyber threat that is one of the most difficult to contend. More importantly, these cyber threats are aggravated by the sheer number of vulnerabilities present in SMPs, the number of available and different types of SMPs (Chaffey, 2016), the poor design and construction of SMPs (Haimson and Hoffmann, 2016), the large volumes of unstructured content (Assunção et al., 2015), and the opportunities that SMPs provide to humans acting in malicious ways (Fire et al., 2014). These factors all contribute to SMPs being extremely vulnerable to cyber threats caused by malicious users. Furthermore, as a result of these cyber threats and SMP vulnerabilities we witness an alarming increase in the prevalence of cyber bullying (Smit, 2015), identity theft (Kabay et al., 2014), identity impersonation (Galán-García et al., 2015), dissemination of pornography (Benevenuto et al., 2010), fraud (Gurajala et al., 2015), and the like. As an example, consider a recent cyber-security case reported on in South Africa where, as in any other country in the world, an alarming increase has been noted in cyber threats related to abuse against women (Bliss, 2017). The cyber threat in this case manifested itself in the form of identity impersonation by two malicious users who exploited the "ease-of-opening-a-deceptive-account" vulnerability on Facebook and were arrested for luring, raping, and killing women (de Villiers, 2017). This and other cybersecurity cases (Peterson, 2016); (Digital, 2016) point to a common thread in exploiting SMP vulnerabilities, namely the ease of creating fake or deceptive identities (Tsikerdekis and Zeadally, 2014).

In the case of identity deception, a deceptive account is either created with malicious intent or to preserve anonymity. This paper is concerned with the detection of deceptive accounts created with malicious intent, as these pose a cyber threat to other humans at large. A deceptive account with malicious intent could for example be used to defame someone's character (Galán-GarcÍa et al., 2015) or conduct online bullying (Smit, 2015). These deceptive accounts are generated by humans or bots (Chu et al., 2010). Much research (Oentaryo et al., 2016); (Dickerson et al., 2014); (Cresci et al., 2015) has been done to detect bot accounts that require no human involvement for the actions they perform. These deceptive bot accounts are known to target groups, as opposed to specific individuals (Oentaryo et al., 2016). However, to date, very little research has focused on detecting deceptive human accounts on SMPs.

The research reported on in this paper is a first attempt at minimising the cyber risk of identity deception as exploited by malicious users on SMPs through the intelligent detection of deceptive identities. The aims of the research reported on in this paper are summarised as follows:

- To identify and describe the different types of information available on SMPs - also referred to as attributes (e.g. the date on which the account is created) - that can potentially be used to detect user identity deception. 
- To experiment with SMP attributes to detect, in an intelligent way, user identity deception by using various machine learning models.

- To enhance the SMP attributes for improving identity deception detection by using engineered features derived from two fields: Firstly, the field of psychology where we focus specifically on discovering why people lie, and secondly, from the field of detecting bot accounts where we intend to determine how these solutions can be leveraged for detecting human identity deception.

- To propose a model that intelligently detects and interprets the perceived deceptiveness of a SMP user, given the results from the aforementioned experiments.

This will be the first time that features derived from the field of psychology will be applied towards the detection of human identity deception on SMPs.

The rest of the paper is organised as follows: Section 2 describes background and related work, Section 3 describes how the SMP data was mined and prepared for experimentation towards detecting human identity deception, Section 4 presents the results from the aforementioned experiments, Section 5 describes the proposed identity deception detection model, and finally, Section 6 concludes with the overall research findings and scope for potential future work.

\section{BACKGROUND AND RELATED WORK}

Cyber threats are widespread, with SMPs being an enabler for cyber attacks (Khandpur et al., 2017). SMPs are vulnerable to cyber threats as they breed trust between individuals without any authority validating or verifying the participants. Cyber crime can potentially have severe consequences. For example, a 14-year-old boy from the UK was groomed online and later killed (Camber, 2014), having been promised "great wealth".

DePaulo et al. (1996) profess that humans are known to lie, for instance about their gender or their age (Drouin et al., 2016). When humans lie about attributes that distinguish them from other humans, it is known as identity deception (Wang et al., 2006).

Much of the past research on identity deception among humans has been psychological in nature and opposing views have been proposed on why humans lie. For example, Halevy et al. (2014) believe that most humans are honest most of the time, whereas DePaulo et al. (1996) are adamant that most humans lie daily, to varying degrees, but mostly in small quantities. Ferrara et al. (2016) believe that the act of deception is deliberate and intended to further a specific goal, such as to recruit other humans for terrorism. Rong et al. (2016) show that incentives such as reward schemes can result in lies being more prevalent. Whilst researchers will continue to debate about when and why humans lie, consensus remains that the act of lying is present. This paper proposes to identify those humans who deceive others on SMPs - with malicious intent - as posited by Ferrara et al. (2016).

For this research past research in psychology was considered to identify those attributes about which humans are most likely to lie; more specifically attributes pertaining to their identity. The hope is that human nature prevails on SMPs and that humans continue to lie, regardless of the medium of communication. Table 1 summarises the conclusions from past research by showing the various identity attributes humans lie about. Evidently, humans lie most often about their image, name, location, age and gender.

From a psychopathological perspective, Stanton et al. (2016) explored whether personality can explain deception such as changing your name or image online. They found that feelings of inadequacy and self-dissatisfaction often lead to deception. Caspi and Gorsky (2006) explored the emotions experienced during deception by using input from different demographics like location, age, gender, marital status, and occupation. They found that identity roleplay and privacy concerns were the main reason for humans being deceptive.

From an online perspective, Hancock (2007) depicted identitybased and message-based deception as two main types of digital deception. He presented a detailed review on why and how humans lie and concluded that deception on online platforms could be more difficult to detect than face-to-face deception. Utz (2005) defined the most common types of deception to be gender switching, identity concealment, and attractiveness deception. He also showed that these deceptive actions could be ascribed to different motivations.

Online dating deception has been the focus of attention of various researchers. For example, Toma et al. (2008) investigated whether humans present themselves truthfully in their online dating profiles. They found that people deliberately deceive and concluded that deception on certain identity attributes such as image, location, age and gender, are more prevalent. (Hancock and Toma, 2009) did similar research on online dating deception but focused on the images presented on these online dating profiles alone. They found that although users often present deceptive pictures, they try to remain authentic as far as possible. For example, users tend to present an image of their younger self.

Besides online deception, identity deception also occurs in other areas such as job interviews and criminology. Jupe et al. (2016) investigated whether verifiable detail provided during a job interview could successfully distinguish humans telling the truth from those who lie. Wang et al. (2006) considered past criminal records and compared the data provided by the criminals with the true data. The knowledge they gained presented a framework to indicate the identity attributes about which these criminals were most likely to lie. It was found that criminals most frequently lied about their name.

Similar identity attributes as those depicted in Table 1 and identified in past psychological research are found to be lied about on SMPs. Appendix A contains a comparison of the attributes identified on the top six SMPs of 2016 (Chaffey, 2016). These attributes can be grouped according to those describing

- the user's account profile, for example his/her profile image;

- information about the account, for example its opening date;

- the behaviour of the user, for example the time at which he/she posted a message on the SMP;

- the user's relationships, for example his/her friends; and 
- the content of the user's posts, for example tweets on Twitter.

\begin{tabular}{|c|c|c|c|c|c|c|c|c|c|c|}
\hline 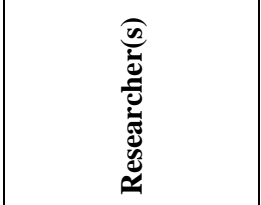 & 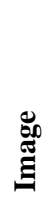 & 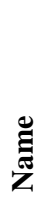 & & 萗 & 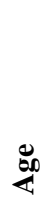 & 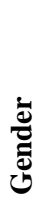 & 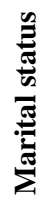 & 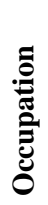 & 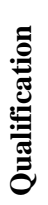 & 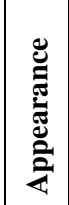 \\
\hline $\begin{array}{l}\text { (Stanton et al., } \\
\text { 2016) }\end{array}$ & $\mathrm{x}$ & $\mathrm{x}$ & & & & & & & & \\
\hline (Jupe et al., 2016) & & & $\mathrm{x}$ & & & & & $\mathrm{x}$ & $\mathrm{x}$ & \\
\hline (Hancock, 2007) & $\mathbf{x}$ & $\mathrm{x}$ & & $\mathrm{x}$ & & $\mathrm{x}$ & & & & \\
\hline \begin{tabular}{|l|} 
Caspi and Gorsky, \\
2006)
\end{tabular} & & & $\mathrm{x}$ & & $\mathrm{x}$ & $\mathrm{x}$ & $\mathrm{x}$ & $\mathrm{x}$ & & \\
\hline$(\mathrm{Utz}, 2005)$ & & $\mathrm{x}$ & & & $\mathrm{x}$ & $\mathrm{x}$ & & & & $\mathrm{X}$ \\
\hline (Toma et al., 2008) & $\mathrm{x}$ & & $\mathrm{x}$ & & $\mathrm{x}$ & $\mathrm{x}$ & & & & \\
\hline \begin{tabular}{|l|} 
Hancock and \\
Toma, 2009) \\
\end{tabular} & $\mathrm{x}$ & & & & & & & & & \\
\hline (Wang et al., 2006) & & $\mathrm{x}$ & $\mathrm{x}$ & & $\mathrm{x}$ & & & & & \\
\hline
\end{tabular}

TABLE 1 . Identity attributes lied about, based on psychological research

For the research in hand, the attributes found in the person's Twitter account were used to detect human identity deception. Twitter is the only platform where no consent from the account holder is required to gather data. By contrast, on Facebook, permission is required from each person before their data can be gathered. (This permission can come in the form of an accepted friend request or the person having opted to become part of a group.) Due to the accessibility of its data, Twitter has been used in many research projects across various disciplines, including for identity deception detection (Gurajala et al., 2016) (Alowibdi et al., 2015). However, since a significant overlap occurs between the attributes of various SMPs (such as the profile image and name), research such as the current, which makes use of data gathered from Twitter, can potentially apply also to another SMP.

Past researchers used the attributes found on SMPs to build new features with which identity deception can be detected. Promising work by Alowibdi et al. (2015) examines identity deception features by detecting inconsistencies in the gender and the expected background colour chosen for the human's account. Alowibdi et al. (2015) also found statistical inconsistencies in geo-location update times that were useful for the detection of deceptive accounts. Tuna et al. (2016) focus on deriving features such as gender and location from the language and the local text used in the content respectively. Other features, such as whether a profile image represents the user truthfully (Hancock and Toma, 2009), similarity of attributes such as name, given the Levenshtein difference ( $\mathrm{Li}$ and Wang, 2015), and the emotional state of a user given the content they post (Bogdanova et al., 2014), have also been posited as being potentially useful for detecting identity deception.
In addition, researchers proposed various techniques to detect identity deception on SMPs. These techniques included filtering (Thomas et al., 2011), rules (Fire et al., 2014), supervised machine learning (Cresci et al., 2015), semisupervised machine learning (Ebrahimi et al., 2016), reinforcement learning (Venkatesan et al., 2017), and unsupervised machine learning ( $\mathrm{Gu}$ et al., 2008). For the purposes of this research, we focused on supervised machine learning, as the problem at hand is one of classifying whether human accounts are to be classified as "deceptive" or "not". Classification problems are typically solved with supervised machine learning (Ma et al., 2014), which is similar to research done in the past to detect bots on SMPs (Cresci et al., 2015); (Oentaryo et al., 2016); (Dickerson et al., 2014). They presented supervised machine learning to solve the problem in classifying an account as "bot" or "not", which has synergies with the current research. Therefore, past research in the detection of bots was used to identify appropriate supervised machine learning algorithms for the research under consideration. In machine learning, no universal algorithm is expected to outperform the rest (Wolpert and Macready, 1997), also referred to as "no free lunch" theorem. Hence, the need exists to test various algorithms on the same problem. Eight machine learning models, found in bot detection research and shown in Table 2, were applied in this research to detect deceptive humans.

\begin{tabular}{|c|c|c|}
\hline $\begin{array}{c}\text { ML } \\
\text { algorithm } \\
\text { name }\end{array}$ & Related research & $\begin{array}{l}\text { ML algorithm } \\
\text { description }\end{array}$ \\
\hline Adaboost & $\begin{array}{l}\text { (Fire et al., 2014); } \\
\text { (Bellinger et al., 2012) }\end{array}$ & $\begin{array}{l}\text { Adaptive boosting } \\
\text { combines the weak results } \\
\text { from various decision trees } \\
\text { to create a boosted } \\
\text { classifier. }\end{array}$ \\
\hline bayesglm & $\begin{array}{l}\text { (Sedhai and Sun, } \\
\text { 2017); (Choudhary and } \\
\text { Jain, 2017) }\end{array}$ & $\begin{array}{l}\text { The Bayesian-generalised } \\
\text { linear algorithm uses } \\
\text { simple logistic regression. }\end{array}$ \\
\hline J48 & $\begin{array}{l}\text { (Choudhary and Jain, } \\
\text { 2017); (Galán-GarcÍa et } \\
\text { al., 2015) }\end{array}$ & $\begin{array}{l}\mathrm{J} 48 \text { is a version of a } \\
\text { decision tree algorithm. }\end{array}$ \\
\hline kknn & $\begin{array}{l}\text { (Ebrahimi et al., 2016); } \\
\text { (Al-garadi et al., 2016) }\end{array}$ & $\begin{array}{l}\text { K nearest neighbours use } \\
\text { clustering to group and } \\
\text { predict similar } \\
\text { classifications. }\end{array}$ \\
\hline nnet & $\begin{array}{l}\text { (Rubin, 2017); (Tuteja, } \\
\text { 2016) }\end{array}$ & $\begin{array}{l}\text { A neural network simulates } \\
\text { the neurons in a brain to } \\
\text { classify. }\end{array}$ \\
\hline $\mathrm{rf}$ & $\begin{array}{l}\text { (Galán-García et al., } \\
\text { 2015); (Tsikerdekis, } \\
\text { 2017) }\end{array}$ & $\begin{array}{l}\text { Random forests build a } \\
\text { number of decision trees to } \\
\text { find the best accuracy with } \\
\text { one such tree. }\end{array}$ \\
\hline rpart & $\begin{array}{l}\text { (Dal Pozzolo et al., } \\
\text { 2013); (Genuer et al., } \\
\text { 2010) }\end{array}$ & $\begin{array}{l}\text { The recursive partitioning } \\
\text { tree is a very basic } \\
\text { representation of a decision } \\
\text { tree. }\end{array}$ \\
\hline svmLinear & $\begin{array}{l}\text { (Tsikerdekis, 2017); } \\
\text { (Peddinti et al., 2017) }\end{array}$ & $\begin{array}{l}\text { SVMs use a high- } \\
\text { dimensional feature space } \\
\text { to classify. }\end{array}$ \\
\hline
\end{tabular}

TABLE 2. Supervised machine learning models 
However, a problem with the results from supervised machine learning models is that these results are seldom interpretable and intuitive (Lipton, 2016). The Financial Times (2017) recently reported on the criticality of being able to explain decisions made from artificial intelligence (AI), as garbage inputs could result in garbage outputs without forewarning. The correct interpretation is for example critical when the detection of deceptive users could have criminal consequences (Burrell, 2016) or a serious impact on people's lives (Ribeiro et al., 2016). The interpretation or explanation of results will become law in the European Union during 2018 and ensure that every European citizen has the right to an explanation where decisions were based on data and algorithms (Goodman and Flaxman, 2016).

The research reported on in this paper introduces the notion of entropy as a potential solution to explain the results from supervised machine learning. In general, entropy refers to uncertainty. Claude Shannon already introduced information entropy in 1948 (Shannon, 2001), where initially it was applied to information compression by determining the quantity of information which can be discarded during transmission before a message becomes irretrievable. This same concept has since been applied to the input of machine learning models (Gurajala et al., 2015), where entropy indicates how much information is gained or lost when input is added or discarded to train machine learning models. The entropy result is helpful to determine the importance of each input for the expected outcome and accuracy of a machine learning model.

\section{PREPARING DATA FOR THE EXPERIMENTS}

\subsection{Gathering the data}

Twitter data was mined to create an initial corpus of social media accounts. The sheer volume of data on Twitter makes mining all account data since the SMP's inception in 2006 unfeasible and impractical for the research at hand. For the purposes of the corpus we chose to limit the data to a demographic known to be the target of deceptive users. Minors are susceptible to cyber bullying (Galán-García et al., 2015), extremist recruitment (Klausen, 2015), and grooming (Kierkegaard, 2008), among others. Therefore, the corpus was limited to accounts that used the words "school" and "homework", as these are words used widely by minors (Schwartz et al., 2013). The friends and followers of these accounts were also mined, as it is known that friends usually have similar friends (Cook, 2014) - in this case, more minors.

223796 Twitter accounts were gathered over a six-month period starting in June 2016. This data, which is publicly available, showed that the accounts were created between 2006 and 2017 and were still actively contributing to Twitter.

\subsection{Cleaning the data}

Since the current research is focused on addressing deception by human users, an attempt was made to rid the corpus of nonhuman accounts included in the initial gathered corpus. To this end, research work presented by Cresci et al. (Cresci et al., 2015), which has shown good results in identifying bots or nonhumans, was applied to clean the data. Cresci et al. identified three sets of rules to distinguish humans from bots. Their top three rules were applied to clean the mined corpus as these rules had an accuracy of over $75 \%$. Their rules required that the account must have

- at least 30 followers;

- at least 50 tweets; and

- replied to at least one direct tweet from another user.

Known celebrities (Twitter, 2017) were also removed from the corpus, as these accounts have been validated by Twitter as being trustworthy. Of the original corpus of 223796 Twitter accounts, 69279 were deemed to be known non-human or verified celebrity accounts. Although some bot accounts might still remain in the cleaned corpus, the researchers believe that the rules applied would have removed most bots with an accuracy of over $75 \%$ (Cresci et al., 2015).

Fig. 1 shows the breakdown of the corpus before and after cleaning. The year indicates when the account was created (i.e. the age of the account). It is noteworthy that the cleaning had a greater effect on accounts created after 2013 than earlier accounts, as the emergence of non-human or bot accounts on SMPs is a relatively recent phenomenon (Oentaryo et al., 2016). After cleaning, 154517 accounts remained in the corpus.

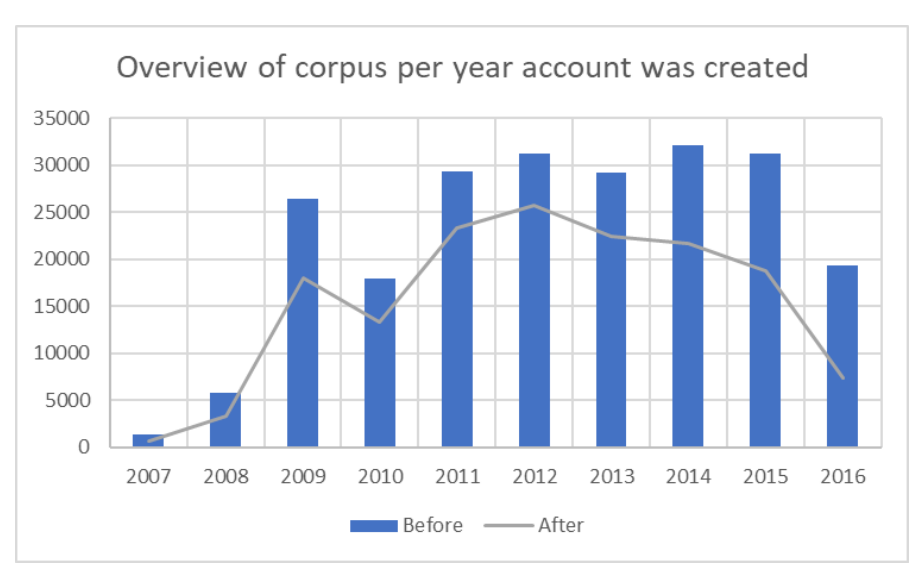

Figure 1: Data before and after cleaning

Finally, certain attributes were also removed to reduce variance and bias. Variance reflects the tendency to learn random things unrelated to the problem (Yarkoni and Westfall, 2016). An example would be if the corpus includes data unrelated to the problem that is being solved, for example the ID assigned to an account by Twitter. Bias is the tendency to learn the same wrong thing (Yarkoni and Westfall, 2016), for example the background image attribute (empty for the gathered corpus and therefore assumed to be always empty) - which is not the case. The following attributes were removed and the reason for removal is shown in brackets:

- Where the attributes were unique to a specific account. - for example, the ID, name, and account description (variance).

- All remaining zero variance attributes were removed, in other words data with a remarkably high ratio of uniqueness - for example, longitude, latitude, and location (variance).

- Data that was mostly empty in the corpus - for example, background image and background colour (bias). 


\subsection{Injecting deceptive accounts}

Supervised machine learning requires a labelled dataset for training purposes. For this reason, known deceptive accounts were injected into the original corpus. There is however a challenge in finding examples of deceptive human accounts. (Zafarani and Liu, 2015) suggested manual crowd-sourcing mechanisms, like Amazon's Mechanical Turk (Amazon, 2017), to label accounts and classify a predicted outcome. Furthermore, there are known means for user groups to oust malicious accounts, like accounts linked to terrorism (Ferrara et al., 2016). Lastly, Peddinti et al. (2017) used labelled datasets from their own previous research work to identify sensitive accounts referring to, for example, topics about pregnancy and paedophilia. None of these options were viable solutions to be used in the current research, due to the absence of known deceptive human accounts and expertise required to manually identify deceptive human accounts correctly as a group. Due to these challenges (if not at all impossible to collect confirmed deceptive accounts in the real world on the Twitter SMP), the choice was made to fabricate deceptive accounts.

The injected deceptive accounts were created using two random human data generator APIs from the internet (Armstrong and Hunt, 2017); (Keen, 2017). Further manual intervention was required to complete the remaining attributes which the APIs could not do. An example of manual data injection was the number of friends and followers of an account. Values were chosen such that they were similar to what was observed within the bounds of the current mined corpus. The deceptive accounts were classified as "deceptive" and the original corpus as "trustworthy".

In an absence of deceptive human accounts and for the sake of the validity of the research, it was decided to ensure that the fabricated deceptive accounts are as far as possible aligned with the data contained in the original corpus. This was done to make the research results as realistic as possible. Most importantly, the following two statistical tests were employed to validate that the injected deceptive accounts were still representative of the original mined corpus:

- Wilcoxon Signed Rank test, also known as the MannWhitney- $U$ test (Kothari, 2004). This test compares the sum of ranks, or indirectly the medians, of two sets of distributions. If the means are similar, the data can be assumed to be from the same population. This test does not require data to be normally distributed or sample sizes to be the same (Mann and Whitney, 1947). For example, evaluate the distribution of one attribute, like "number of friends" for both the "deceptive" and "trustworthy" corpus. If both distributions are found to be similar, they are believed to represent similar data. If all attributes individually pass the Wilcoxon test, both datasets can be said to be from the same population, which is in this case Twitter.

- Pearson's chi-square test of independence (Kothari, 2004). This test assumes that subjects in a single population are classified similarly. This test will show when attributes in the population are correlated, and thus from the same population. This test works well when samples were generated at random; the attributes were categorical; and the resultant categories were greater than 5 (McDonald, 2009). Per example, evaluate the correlation between one attribute, such as "number_of_friends" for both the "deceptive" and "trustworthy" corpus. If the attribute is found to be highly correlated, it can be said that attribute contain similar data. If all attributes succeed in the Pearson's Chi square test, it can be said that both datasets are from the same population, in this case Twitter.

For this research the injected deceptive accounts were not only representative of data found in Twitter, but also had to be actually deceptive. For this reason, past research from the field of psychology, highlighting identity attributes humans are known to lie about were analysed. It was found that humans lie most often about their image, name, location, age, and gender. Therefore, we confirmed that each injected deceptive account was deceptive in respect of each of these attributes by applying rules to test for deceptiveness. An example was to ensure that the name used for an account and its pseudonym was never the same. Another was that the age detected in the user's image was different from their actual age. By ensuring that all attributes, as per psychological identity deception research results, were deceptive, each account was created to be as deceptive as possible - even though humans might lie only about some of these attributes in the real world.

Over 15000 fabricated deceptive accounts were injected, which constituted almost $10 \%$ of the corpus. Halevy et al. (2014) found that $5 \%$ of people tell $40 \%$ of all lies. With the introduction of $10 \%$ fabricated deceptive accounts most lies should be catered for.

\subsection{Preparing data for machine learning}

Before any machine learning models can be trained towards identity deception, the data must be in the correct format. Most machine learning models expect data to be discretised, centred, and scaled (Kuhn et al., 2016). Discretisation implies that numerical data is converted to categorical data. An example is if the number of friends is grouped into bins of 500. The result would be accounts falling into the ranges of 0-500, 501-1000, and so on. All nominal values are then centred. For centring, the sample mean is subtracted. For example, if the mean of the "number_of_friends" is 1500 for the total corpus, this value will be subtracted from each account for their respective "number_of_friends". Lastly, these centred values are divided by the standard deviation. This ensures that all input is similarly scaled and will not introduce bias if the values for other inputs are higher. An example is where the number of friends is on a different scale initially from the number of tweets or posts. The proposed scaling method ensures that machine learning models will treat both inputs as equally important.

\section{DETECTING IDENTITY DECEPTION}

As described earlier, a corpus was created by gathering data from Twitter, cleaning it, and injecting deceptive accounts. The next step involved using the corpus as input to train machine learning models in detecting identity deception. For this, two experiments were defined:

- Experiment 1: Only data from the corpus was used to detect identity deception. This data was based on the original attributes as found in Twitter, for example their 
"number_of_friends", also denoted as FRIENDS_COUNT in Twitter.

- Experiment 2: The original attributes used in Experiment 1 were then extended upon with new engineered features. These features were engineered from psychological principles that identify deception and included previously engineered features that were applied to detect non-human or bot accounts. An example of such a feature is "gender". This feature uses the original SMP attributes, namely the name and profile image of the account. The "gender" feature shows the correlation between the gender derived from each individual attribute. The intention of the second experiment was to evaluate whether these features could possibly improve the accuracy of identity deception detection by humans on SMPs (results of Experiment 1).

\subsection{Results of detecting identity deception}

\subsubsection{Experiment 1}

After removing attributes from the corpus to avoid bias and variance, only a few viable SMP attributes remained given the original attributes described in appendix A. Regardless, the previously identified supervised machine learning algorithms were trained to determine whether these attributes could detect human identity deception. These machine learning algorithms were trained using 3-repeat, 10-fold, cross validation (Anguita et al., 2012) and the default parameters as defined by the caret package in R (Kuhn et al., 2016). The results from these machine learning models, built from the attributes in Twitter only, are shown in Table 3. The accuracy measure can be deceptive in skewed datasets such as the current corpus. The F1 score was selected as the indicative metric of performance as it includes precision (the number of the predicted deceptive accounts that were actually deceptive) and recall (the number of actual deceptive accounts which were identified correctly). The PR-AUC metric shows the area under the precision recall curve. Lastly, cost was added as an additional metric to describe how many seconds were required to execute each machine learning model.

The results in Table 3 show that the random forest (rf) model detected identity deception with a F1 score of $32.92 \%$. The Adaboost model performed next best, with an F1 score of $29.51 \%$. Thus, the rf model could be preferred to the Adaboost model, as the former can be trained much faster and shows better results. Table 3 also shows that the attributes used to train the machine learning models did not predict human identity deception successfully. The machine learning models performed worse than selecting the prediction at random (which has a $50 \%$ chance of success).

\begin{tabular}{|l|l|c|l|l|}
\hline ML model & Accuracy & $\begin{array}{c}\text { F1 } \\
\text { Score }\end{array}$ & PR-AUC & \multicolumn{1}{c|}{ Cost } \\
\hline svmLinear & $16.01 \%$ & $16.28 \%$ & $8.47 \%$ & 68.257 \\
\hline rf & $79.94 \%$ & $32.92 \%$ & $29.25 \%$ & 101.842 \\
\hline J48 & $70.07 \%$ & $28.08 \%$ & $21.79 \%$ & 110.317 \\
\hline bayesglm & $66.75 \%$ & $15.12 \%$ & $9.84 \%$ & 4.047 \\
\hline kknn & $71.17 \%$ & $23.91 \%$ & $13.30 \%$ & 62.317 \\
\hline
\end{tabular}

\begin{tabular}{|l|l|l|l|l|}
\hline Adaboost & $77.89 \%$ & $29.51 \%$ & $32.27 \%$ & 891.145 \\
\hline rpart & $66.03 \%$ & $23.65 \%$ & $13.55 \%$ & 3.759 \\
\hline nnet & $63.34 \%$ & $25.74 \%$ & $32.05 \%$ & 38.897 \\
\hline
\end{tabular}

TABLE 3: Machine learning results for Experiment 1 Much could nonetheless be learnt from these results - more specifically, which attributes were more important than others. This was achieved by investigating the entropy of each attribute used to train the machine learning model. Entropy (Shannon, 2001) indicates how much information is gained - in this case a better detection of identity deception - by introducing that specific attribute. If $\mathrm{p}$ is the probability of $\mathrm{A}$, given $\mathrm{n}$ attributes; then entropy can be calculated as follows:

$$
H(\boldsymbol{A})=-\sum_{i=1}^{n} p_{i} \log _{2} p_{i}
$$

(Shannon, 2001)

Table 4 shows the entropy results of the top three machine learning models based on the F1 scores. The entropy values are depicted as a value between 0 and 100, with 100 indicating that the model was highly dependent on the attribute and 0 meaning that the attribute had very little influence on the outcome.

\begin{tabular}{|r|r|r|r|}
\hline \multicolumn{1}{|c|}{ Attributes } & \multicolumn{1}{c|}{$\begin{array}{c}\text { rf } \\
\text { entropy } \\
\text { result }\end{array}$} & $\begin{array}{c}\text { J48 } \\
\text { entropy } \\
\text { result }\end{array}$ & $\begin{array}{c}\text { Adaboost } \\
\text { entropy } \\
\text { result }\end{array}$ \\
\hline FOLLOWERS_COUNT & 100.00 & 0.00 & 0.00 \\
\hline FRIENDS_COUNT & 80.88 & 72.30 & 72.30 \\
\hline LISTED_COUNT & 0.00 & 28.61 & 28.61 \\
\hline STATUS_COUNT & 79.11 & 44.61 & 44.61 \\
\hline TIMEZONE & 41.43 & 100.00 & 100.00 \\
\hline
\end{tabular}

TABLE 4: Entropy results for Experiment 1

The entropy results in this experiment showed that all attributes, except for the LISTED_COUNT attribute, played some part in the predictions at some point or another. According to Cresci et al. (2015), these attributes were also known to successfully detect bot accounts; hence attributes previously used in the detection of bots can be applied equally well to detect human deception. The bot attributes and new features engineered from psychology will be introduced during Experiment 2 in the hope of improving the results achieved during Experiment 1.

\subsubsection{Experiment 2}

For the second experiment, the original corpus data (based on original Twitter attributes) was extended with new engineered features. The entropy results from Experiment 1 already suggested that past research in bot detection could be used to detect human identity deception (Van der Walt and Eloff, 2018). In addition, the field of psychology was consulted to engineer features that could indicate human identity deception. These features were engineered using the attributes of Twitter as presented in Appendix A. Table 5 lists all newly engineered features, whether originating from past research into bot detection or from the field of psychology. It also shows which 
Twitter attributes were used and/or combined to construct the feature.

Next follows a brief description of each attribute:

- ACCOUNT_AGE_IN_MONTHS - This feature shows the number of months since the account was opened.

- AGE - For this feature, the discrepancy between the age of the account and the age of the user was calculated. If AGE contributes to deception, the calculated ages for deceptive accounts will be different from those of in the trustworthy corpus. The age of the user was determined using the Google Vision API (Google, 2017). This API can extract faces and their age from any given image by using Google's own proprietary machine learning models for those accounts that have images.

- GENDER - Google Vision API (Google, 2017) was used to determine whether the face shown on a profile image was male or female. Combining this knowledge with a name database (of male and female names) creates a feature that can compare the gender of an image to the gender of a name.

- DISTANCE_LOCATION - In Twitter, the geo-tag of the last tweet is stored for geo-enabled users. This feature uses the geo-location lookup API to retrieve the location given in the status of the user. This location is compared with the geo-tag. The Haversine distance (Van Liere, 2010) (Shumaker and Sinnott, 1984) between the two determines the feature value.

- DISTANCE_TZ - Twitter also stores the time zone of the user. This time zone is captured during registration and can be changed by users at any time. The feature employs the geo-location lookup API to retrieve the location given in the status of the user and then compares it with the stated time zone of the user. The Haversine distance (Van Liere, 2010) (Shumaker and Sinnott, 1984) between the two determines the feature.

- DUP_PROFILE - This feature shows whether the current account has a similar profile description as another.

- FRIENDS_VS_FOLLOWERS - The ratio of friends vs followers is determined for this feature.

- FOLLOWERS_COUNT - In Twitter, the number of followers is recorded for each account. This value was discretised for the current experiment.

- FRIENDS_COUNT - The number of friends - also recorded for each account in Twitter - was discretised for the experiment in hand.

- GEO_ENABLED - Twitter stores whether an account is enabled to store its location in terms of longitude and latitude.

- HAS_IMAGE - This feature is constructed as a binary indicator and shows whether a profile image has been defined for an account or whether the account is still using the default Twitter image as its profile.

- HAS_NAME - This feature is constructed as a binary indicator showing whether the name could be found in a name database.

- HAS_PROFILE - This feature is constructed as a binary indicator showing whether the account has a description or not.
- NAME - The Levenshtein distance (Li and Wang, 2015) (Levenshtein, 1966) between the screen-name and registered username.

- LISTED_COUNT - In Twitter the number of public lists the account belongs to is recorded. This value is discretized for the experiment at hand.

- PROFILE_HAS_URL - This feature is constructed as a binary indicator showing whether the account's description contains an URL or not.

- TWEET_COUNT - The number of tweets posted by the account are discretized for the experiment at hand.

- NAME_LENGTH - The number of characters contained in the screen name or pseudonym of the account.

\begin{tabular}{|c|c|c|}
\hline Feature & Origin & $\begin{array}{c}\text { Constructed } \\
\text { from these } \\
\text { Twitter } \\
\text { attributes }\end{array}$ \\
\hline ACCOUNT_AGE_IN_MONTHS & Bot & created_at \\
\hline AGE & Psychology & $\begin{array}{l}\text { created_at, } \\
\text { profile_image }\end{array}$ \\
\hline GENDER & Psychology & $\begin{array}{l}\text { name, } \\
\text { profile_image }\end{array}$ \\
\hline DISTANCE_LOCATION & Psychology & $\begin{array}{l}\text { location, latitude, } \\
\text { longitude }\end{array}$ \\
\hline DISTANCE_TZ & Psychology & $\begin{array}{l}\text { location, } \\
\text { time_zone }\end{array}$ \\
\hline DUP_PROFILE & Bot & description \\
\hline FRIENDS_VS_FOLLOWERS & Bot & $\begin{array}{l}\text { friends_count, } \\
\text { followers_counts }\end{array}$ \\
\hline FOLLOWERS_COUNT & Bot & followers_count \\
\hline FRIENDS_COUNT & Bot & friends_count \\
\hline GEO_ENABLED & Bot & geo_enabled \\
\hline HAS_IMAGE & Bot & profile_image \\
\hline HAS_NAME & Bot & Name \\
\hline HAS_PROFILE & Bot & description \\
\hline NAME & Psychology & $\begin{array}{l}\text { name, } \\
\text { screen_name }\end{array}$ \\
\hline LISTED_COUNT & Bot & listed_count \\
\hline PROFILE_HAS_URL & Bot & description \\
\hline TWEET_COUNT & Bot & status_count \\
\hline NAME_LENGTH & Bot & screen_name \\
\hline
\end{tabular}

TABLE 5: Features engineered for Experiment 2

Together, these features were used to train the same 8 supervised machine leaning models used for experiment 1 . The results from these machine learning models are shown in Table 6. The Adaboost model achieved an F1 score of $84.65 \%$ and random forest (rf) achieved an F1 score of $86.24 \%$. These results were considerably better than those achieved using Twitter attributes alone (Experiment 1).

\begin{tabular}{|l|r|r|r|r|}
\hline $\begin{array}{c}\text { ML } \\
\text { Model }\end{array}$ & Accuracy & F1 Score & PR-AUC & \multicolumn{1}{c|}{ Cost } \\
\hline svmLinear & $92.20 \%$ & $66.29 \%$ & $76.80 \%$ & 45.198 \\
\hline rf & $97.49 \%$ & $86.24 \%$ & $93.00 \%$ & 157.801 \\
\hline J48 & $95.79 \%$ & $79.05 \%$ & $64.94 \%$ & 178.649 \\
\hline bayesglm & $92.07 \%$ & $65.85 \%$ & $77.01 \%$ & 6.932 \\
\hline kknn & $94.18 \%$ & $72.93 \%$ & $81.32 \%$ & 80.933 \\
\hline
\end{tabular}




\begin{tabular}{|l|r|r|r|r|} 
Adaboost & $97.03 \%$ & $84.65 \%$ & $93.70 \%$ & 2127.87 \\
\hline rpart & $87.32 \%$ & $55.83 \%$ & $38.29 \%$ & 5.091 \\
\hline nnet & $95.21 \%$ & $76.94 \%$ & $87.76 \%$ & 62.796 \\
\hline
\end{tabular}

TABLE 6: Machine learning results for Experiment 2

Table 7 shows the entropy results of the top three machine learning models. These results show which features contributed most significantly in the final machine learning model. AGE, NAME, HAS_NAME, HAS_PROFILE, DUP_PROFILE, NAME_LENGTH, and DISTANCE_TZ showed most promise as features indicative of human identity deception. These features coincide with what we know from psychology in that humans lie about the image, name, location, and age. It seems that gender was a poor indicator of deceptiveness. This could be due to the fact that the images in Twitter are in general misrepresentative of the users, and the trained models were thus unable to use this specific feature to identify human identity deception.

\begin{tabular}{|r|r|r|r|}
\hline \multicolumn{1}{|c|}{ Features } & \multicolumn{1}{|c|}{$\begin{array}{c}\text { rf } \\
\text { entropy } \\
\text { result }\end{array}$} & $\begin{array}{c}\text { J48 } \\
\text { entropy } \\
\text { result }\end{array}$ & $\begin{array}{c}\text { Adaboost } \\
\text { entropy } \\
\text { result }\end{array}$ \\
\hline ACCOUNT_AGE_IN_MONTHS & 15.23 & 37.66 & 37.66 \\
\hline AGE & $\mathbf{1 0 0 . 0 0}$ & $\mathbf{1 0 0 . 0 0}$ & $\mathbf{1 0 0 . 0 0}$ \\
\hline GENDER & 17.80 & 12.29 & 12.29 \\
\hline DISTANCE_LOCATION & 0.13 & 0.95 & 0.95 \\
\hline DISTANCE_TZ & $\mathbf{1 8 . 6 1}$ & $\mathbf{5 3 . 1 3}$ & $\mathbf{5 3 . 1 3}$ \\
\hline DUP_PROFILE & $\mathbf{2 8 . 2 4}$ & $\mathbf{6 4 . 3 4}$ & $\mathbf{6 4 . 3 4}$ \\
\hline FRIENDS_VS_FOLLOWERS & 0.33 & 0.90 & 0.90 \\
\hline FOLLOWERS_COUNT & 8.41 & 8.50 & 8.50 \\
\hline FRIENDS_COUNT & 6.12 & 17.10 & 17.10 \\
\hline GEO_ENABLED & 4.81 & 13.80 & 13.80 \\
\hline HAS_IMAGE & 0.00 & 0.72 & 0.72 \\
\hline HAS_NAME & $\mathbf{5 7 . 8 3}$ & $\mathbf{7 9 . 9 1}$ & $\mathbf{7 9 . 9 1}$ \\
\hline HAS_PROFILE & $\mathbf{2 6 . 1 6}$ & $\mathbf{6 1 . 5 9}$ & $\mathbf{6 1 . 5 9}$ \\
\hline LISTED_COUNT & 0.63 & 0.00 & 0.00 \\
\hline PROFILE_HAS_URL & 4.21 & 9.86 & 9.86 \\
\hline TWEET_COUNT & 7.92 & 8.86 & 8.86 \\
\hline NAME_LENGTH & $\mathbf{2 5 . 5 9}$ & $\mathbf{2 7 . 7 4}$ & $\mathbf{2 7 . 7 4}$ \\
\hline & & & \\
\hline & $\mathbf{5 9 . 2 7}$ & $\mathbf{8 1 . 5 5}$ & $\mathbf{8 1 . 5 5}$ \\
\hline
\end{tabular}

TABLE 7: Entropy results for Experiment 2

\section{IDENTITY DECEPTION DETECTION MODEL (IDDM) FOR SMPs}

IDDM provides automated assistance for the detection of identity deception on SMPs. Based on the experimental results discussed in the previous sections IDDM is structured to consist of the following 2 sub-models:

(1) Identity Deception Detection Machine Learning Model (IDDMLM). The IDDMLM employs machine learning to identify appropriate attributes and features of identity related information on SMPs. IDDMLM calculates accuracy and entropy information of these attributes and features. IDDMLM determines if an identity is deceptive or not. Because of its machine learning nature, it provides little interpretation as to why an identity is perceived as deceptive or not.

(2) Identity Deception Detection Score Model (IDDSM). The IDDSM uses the outputs of the IDDMLM. These outputs include the accuracy and entropy related information about attributes and features. The entropy information is used by IDDSM to determine the importance of attributes and features. This information is then used as weighted variables in a linear formula which determines if an identity is deceptive or not. Furthermore, the model then provides an interpretation as to why an identity is deceptive or not.

\subsection{The IDDMLM sub-model}

IDDMLM uses the Random Forest algorithm, which is a collection of randomized decision trees (Biau, 2012). IDDMLM is represented as follows:

Let $\mathrm{SMP}=\left\{\mathrm{SMP}_{\mathrm{i}}: \mathrm{SMP}_{\mathrm{i}}\right.$ is a Social Media Platform $\}$

Let $A=\left\{a_{1}, a_{2}, \ldots, a_{n}\right\}$ be subset of $S_{M P}$ attributes,

with $\mathrm{n}<$ the number of attributes in $\mathrm{SMP}_{\mathrm{i}}$

Where:

A is periodically created,

$\mathrm{A}=\mathrm{A}^{1} \cup \mathrm{A}^{2}$,

$A^{1}=\left\{a_{1}, a_{2}, \ldots, a_{n}\right\}$ is a random extracted training data set with number of deceptive examples $=$ number of not deceptive examples,

$A^{2}=\left\{a_{1}, a_{2}, \ldots, a_{n}\right\}$ is a random extracted test data set with $\sum$ deceptive examples $=\sum$ not deceptive examples,

Note: It is typical for A to be created and thereafter split into training and test data where $\mathrm{A}^{1}$ contains $75 \%$ of $\mathrm{A}$ and the remaining $25 \%$ belongs to $\mathrm{A}^{2}$ (Menardi and Torelli, 2014).

Let $F=\left\{f_{1}, f_{2}, \ldots, f_{m}\right\}$ be a set of features,

$\mathrm{m}=$ number of engineered features

Where:

$\mathrm{f}_{\mathrm{i}} \in \mathrm{A} \vee \mathrm{f}_{\mathrm{i}}=f\left(\mathrm{a}_{\mathrm{j}}, \ldots, \mathrm{a}_{\mathrm{k}}\right)$

Where:

$$
\mathrm{j} \geq 1
$$$$
\mathrm{k} \leq \mathrm{n} \text {. }
$$

Let $R F=\left\{h\left(x \mid \Theta_{1}\right), h\left(x \mid \Theta_{2}\right), \ldots, h\left(x \mid \Theta_{t}\right)\right\} \quad$ (Breiman, 2001) Where:

$\mathrm{RF}=$ Random Forest algorithm,

$\mathrm{t}=$ number of decision trees,

$\mathrm{h}\left(\mathrm{x} \mid \Theta_{\mathrm{i}}\right)=$ a single decision tree

Where:

$$
\begin{aligned}
& \Theta_{i} \subseteq\left(\left(F \mid A^{1}\right) \cup A^{1}\right), \\
& x=\text { the values of } A^{1} \vee F \text { given } \Theta_{i}, \\
& 1 \leq \mathrm{i} \leq \mathrm{t} .
\end{aligned}
$$

Note:

For the final classification each decision tree $\mathrm{h}\left(\mathrm{x} \mid \Theta_{\mathrm{i}}\right)$ casts a vote for the most popular output, given input $\mathrm{x}$. The class with the most votes win. There is no indication of which $h\left(x \mid \Theta_{i}\right)$ 's votes won and also votes differ for each input 
given. This issue is known as the machine learning interpretability problem (Ribeiro et al., 2016).

Let $\mathrm{RF}_{\text {Results }}=\left\{\left(\mathrm{f} 1_{\mathrm{i}}, \mathrm{e}_{\mathrm{i}}\right)\right.$ : calculated for

$\left.\forall\left(\mathrm{a}_{\mathrm{i}} \vee \mathrm{f}_{\mathrm{i}}\right) \in \Theta\right\}$

(Biau, 2012)

Where:

$\mathrm{RF}_{\text {Results }}=$ Results of Random Forest,

$$
\mathrm{fl}_{\mathrm{i}}=\text { an F1 value, (Jeni et al., 2013) }
$$$$
\mathrm{e}_{\mathrm{i}}=\text { an Entropy value. (Rényi, 1961) }
$$

Let $A^{3}=\left\{a_{i} \vee f_{i}\right.$ : selected based on optimum values out of the set generated by $\left.f\left(\mathrm{f}_{\mathrm{i}}, \mathrm{e}_{\mathrm{i}}\right)\right\}$

(Breiman, 2001)

Where:

$$
\begin{aligned}
& 1<\mathrm{i} \leq \mathrm{n}, \\
& \mathrm{A}^{3} \subseteq \mathrm{A} .
\end{aligned}
$$

Let $\mathrm{M}_{\mathrm{i}}=$ final Identity Deception Score (IDS) for $\mathrm{U}_{\mathrm{p}}$ Where:

$$
\begin{aligned}
& U_{p} \text { is a user of } S_{M P}, \\
& M_{i}=R_{p}=\left\{h\left(x_{p} \mid \Theta_{1}\right), h\left(x_{p} \mid \Theta_{2}\right), \ldots, h\left(x_{p} \mid \Theta_{t}\right)\right\}, \\
& x_{p}=\text { values of }\left\{a_{i} \vee f_{i}\right\} \in A^{3} \text { for } U_{p} .
\end{aligned}
$$

\subsection{The IDDSM sub-model}

The IDDSM sub-model uses the output of the IDDMLM submodel. IDDSM includes interpretation as to why the identity of a SMP user is perceived as deceptive or not.

The IDDSM is represented as follows:

Let $S_{i}$ be the Identity Deception Score (IDS) for $U_{p}$ Then

$$
S_{i}=>\sum_{i=1}^{m} f\left(w, x_{p}\right)_{i}
$$

Where:

$$
\begin{aligned}
& \mathrm{m}=\text { number of elements }\left\{\mathrm{a}_{\mathrm{i}} \vee \mathrm{f}_{\mathrm{i}}\right\} \text { in } \mathrm{A}^{3}, \\
& f\left(\mathrm{w}, \mathrm{x}_{\mathrm{p}}\right)=\mathrm{w}\left|\mathrm{x}_{\mathrm{p}}\right|, \\
& \mathrm{w} \in[0,100], \\
& \mathrm{x}_{\mathrm{p}}=\text { values of }\left\{\mathrm{a}_{\mathrm{i}} \vee \mathrm{f}_{\mathrm{i}}\right\} \in \mathrm{A}^{3} \text { for } \mathrm{U}_{\mathrm{p}}, \\
& \mathrm{w}=\mathrm{e}_{\mathrm{i}} \in \mathrm{A}^{3}
\end{aligned}
$$

If $S_{i} \sim M_{i}$ then $w$, together with $x_{p}$ can be used to interpret the results of $\mathrm{M}_{\mathrm{i}}$ for $\mathrm{U}_{\mathrm{p}}$.

\subsection{Illustrating the working of IDDM}

Table 8 shows IDDMLM results for two identities, with some features obfuscated due to privacy and ethical reasons. These identities were taken from the original corpus of Twitter data used for experiments one and two, as earlier discussed in this paper. One of the identities was determined to be trustworthy and the other one not.

\begin{tabular}{|l|r|r|}
\hline $\begin{array}{l}\text { SMP Attributes and } \\
\text { Features }(\mathbf{A})\end{array}$ & Deceptive $\left(\mathbf{U}_{\mathbf{1}}\right)$ & Not Deceptive $\left(\mathbf{U}_{\mathbf{2}}\right)$ \\
\hline ** ID & $? ? ?$ & $? ? ?$ \\
\hline ** SCREENNAME & $? ? ?$ & $? ? ?$ \\
\hline ** PROFILE_IMAGE & $4,416.31$ & $? \mathbf{y}$ \\
\hline DISTANCE_TZ & 10.57 & $1,382.00$ \\
\hline AGE & 9.00 & 40.72 \\
\hline NAME & 10.00 & 9.00 \\
\hline NAME_LENGTH & 1.00 & 12.00 \\
\hline HAS_PROFILE & - & 1.00 \\
\hline DUP_PROFILE & 1.00 & - \\
\hline HAS_NAME & $94.80 \%$ & 1.00 \\
\hline *IDDMLM & & $2.40 \%$ \\
\hline
\end{tabular}

* $\mathrm{ID}_{\mathrm{t}}$ : high $\%=$ more deceptive

$* *$ Obfuscated for ethical reasons

TABLE 8: Results from the IDDMLM model

To validate the IDDMLM results, shown in Figure 2, a subset of tweets for each individual are presented for clarity. This is shown in Figure 2.

\begin{tabular}{|l|}
\hline @infectionmalik. Follow me pleasee \\
@iswaaag. Follow me please \\
@VictorManuel03_follow me please \\
@KevinArzate thanks \\
@KevinArzate follow me please \\
@VictorManuel03_follow me please \\
@cesarraejepsen follow back please \\
@PedroNegrini follow me please! \\
@justinbieber follow me please please. I love u too
\end{tabular}

(a) Deceptive $\left(U_{1}\right)$

@s thank you... merry Christmas!!!!! Have the best holiday.

@PM ..perfect timing.. lol

@a thank you!!! Happy Thursday!!!

Have a very merry blessed Thursday..

\#Oregon \#GoDucks fans

Love doesn't make the world go round

@et ..power was problem for most.. some areas still had solar and cell phones

@et ...yep... 110\% She wasn't the only.. just the most famed

(b) Not Deceptive $\left(\mathrm{U}_{2}\right)$

Figure 2: Tweets for individual users (U)

Given these tweets shown in Figure 2, it is clear why the first individual could be perceived as trolling the profiles of celebrities and being deceptive, and the second not. Although the conclusion is still perhaps subjective, the IDDMLM model was able to identify potential identity deceptiveness.

The IDDSM proposes to explain the decisions given by IDDMLM. Figure 3 shows the entropy values determined by $\mathrm{RF}_{\text {Result }}$ in the form of $\mathrm{A}^{3}$. The entropy results are indicated by values between 0 and 100 with the latter being most influential. $\mathrm{A}^{3}$ was subsequently used in the IDDSM towards identity deception detection. 


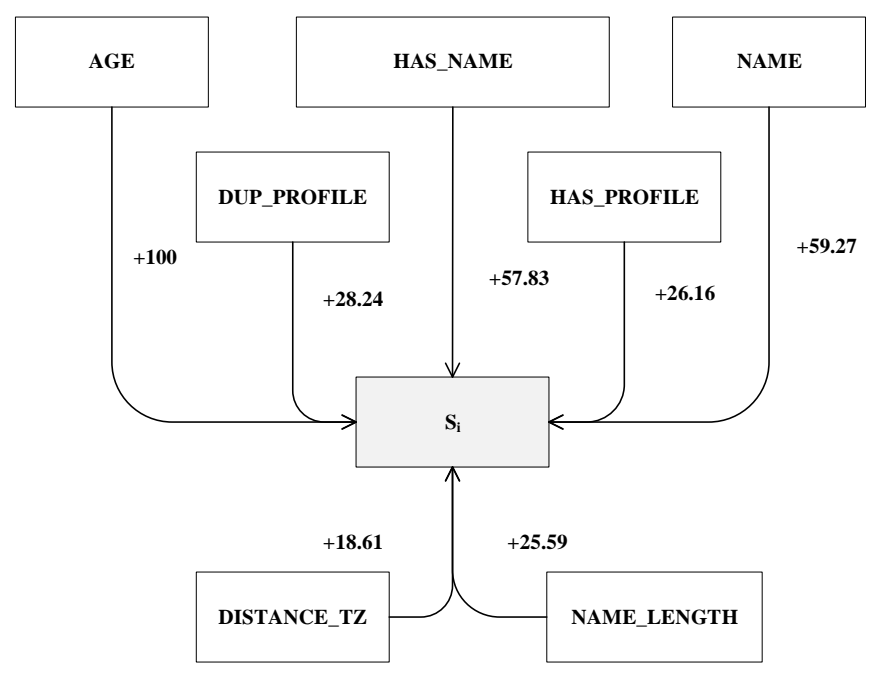

Figure 3: The IDDSM sub-model

Using the same examples (Table 8) as for the IDDMLM submodel, Table 9 presents the results according to the IDDSM sub-model where entropy was added to highlight (with color) those features most indicative of the deceptiveness. The IDDSM results therefore adds an interpretation feature to our IDDM model.

\begin{tabular}{|r|l|l|}
\hline $\begin{array}{l}\text { SMP Attributes and } \\
\text { Features }\left(\mathbf{A}^{\mathbf{3}}\right)\end{array}$ & Deceptive $\left(\mathbf{U}_{\mathbf{1}}\right)$ & Not Deceptive $\left(\mathbf{U}_{\mathbf{2}}\right)$ \\
\hline AGE & & \\
\hline DISTANCE_TZ & & \\
\hline NAME & \\
\hline NAME_LENGTH & \\
\hline HAS_PROFILE & \\
\hline DUP_PROFILE & \\
\hline HAS_NAME & \\
\hline
\end{tabular}

TABLE 9: IDDSM results

\subsection{Comparing IDDM with other models}

The IDDM model differs from other proposed machine learning interpretation models in that the results require no further machine learning or repetitive processing. The LIME model (Ribeiro et al., 2016), for example, generates additional local values for each user, similar but not equal to the original. All values for a particular user, are then trained, ignoring the values of other users, with a linear supervised machine learning algorithm. If the original cost of one iteration of a supervised machine learning model is represented as $\mathrm{O}(1)$, then the cost of the LIME model would be $\mathrm{O}(1+n)$, for $n$ users as a separate machine learning model is trained additionally for each user. The result is a local linear explanation specific to each user. Baehrens et al. (2010) followed a similar local approximation approach at the same cost as LIME, but by generating new local values using a different method. Besides linear interpretation models, others propose to use game theory (Beillevaire, 2016). With game theory, the Shapely value (Shapley, 1953) shows promise by calculating all potential outcomes using different combinations of inputs. This, however, becomes computationally expensive when many inputs are used. The cost can be represented as $\mathrm{O}(\mathrm{k}$ !) with $\mathrm{k}$ the number of inputs. There are other machine learning interpretation models that are dependent on the machine learning model used. An example for such a model is the 'treeinterpreter' (Saabas, 2018) which uses the knowledge gathered from all trees in a random forest to interpret the final result for a user. In this scenario the cost can be represented as $\mathrm{O}(\mathrm{t})$ where $\mathrm{t}$ is the number of random forest trees generated by the model during training.

The IDDM presented in this paper, on the other hand, proposes to only use the results from the original trained supervised machine learning model. No further computations are required. The cost of the IDDM thus remains $\mathrm{O}(1)$ which is imperative for SMPs dealing with large volumes of data.

\section{CONCLUSION AND FUTURE WORK}

Cyber security in general can benefit from the research work presented in this paper which deals with the development of intelligent identity deception detection by means of machine learning models. An Identity Deception Detection Model (IDDM) was proposed to not only detect, but also interpret perceived deceptiveness. The model consists of two submodels.

The first sub-model, IDDMLM, used input from prior experiments to present a machine learning model that detects identity deception on SMPs with an F1 score of $86.24 \%$. This result was achieved using engineered features identified for the detection of bots, as well as new features based on insights from the field of Psychology. The entropy values extracted from the results furthermore shows the contribution of each feature which was then applied by the second sub-model. The IDDSM interpreted the results from IDDMLM by means of a simple weighted linear formula, given the known entropy of the features involved. The IDDSM results highlighted which features a specific user was found to be most likely deceptive about. This is invaluable in use cases where that particular user should be investigated further. It was also shown how the cost of IDDSM remains $\mathrm{O}(1)$. This low-cost interpretative model is valuable in scenarios where near real-time results are required in big data environments.

Given what was learned from this research, the following recommendations can be made to address the vulnerabilities of SMP platforms so as to improve the environment for the intelligent detection of deceptive identities:

- The engineered features as identified in this paper (such as name_length) can be added as default attributes in the creation of user accounts on SMPs. This modification will save on computational workload when intelligent models, such as IDDM, are employed to detect human identity deception.

- The sub-set of existing attributes that are compulsory for users to complete during the creation of an account (e.g. the user's location) should be expanded. This information need not be public knowledge, so that the person's privacy is protected.

- Validation mechanisms can be added during account creation or updates to ensure the authenticity of the 
information that is provided. Profile images can, for example, be validated to ensure they contain the image of a person.

Future research work proposes to identify more features valuable towards the detection of identity deception detection on SMPs including the refinement of the IDDM.

\section{ACKNOWLEDGEMENTS}

We would like to thank the HPI Future SOC research lab in Potsdam, Germany for its assistance and support during the research. The lab provided the research environment to not only mine and store the Twitter data, but also to execute the experiments.

\section{BIBLIOGRAPHY}

AL-GARADI, M. A., VARATHAN, K. D. \& RAVANA, S. D. 2016. Cybercrime detection in online communications: The experimental case of cyberbullying detection in the Twitter network. Computers in Human Behavior, 63, 433-443.

ALOWIBDI, J. S., BUY, U. A., PHILIP, S. Y., GHANI, S. \& MOKBEL, M. 2015. Deception detection in Twitter. Social Network Analysis and Mining, 5, 1-16.

AMAZON. 2017. Mechanical Turk. Available: https://www.mturk.com/ [Accessed 8 Jan 2018].

ANGUITA, D., GHELARDONI, L., GHIO, A., ONETO, L. \& RIDELLA, S. The ' $\mathrm{K}$ 'in K-fold cross validation. Proceedings, European Symposium on Artificial Neural Networks, Computational Intelligence and Machine Learning. Bruges (Belgium), 2012. 441-446.

ANONYMOUS. 2017. Ceding powers of decision to AI presents a paradox. Financial Times [Online]. Available: https://www.ft.com/content/63542534-ebf6-11e7-bd17521324c81e23 [Accessed 4 Jan 2018].

ARMSTRONG, K. \& HUNT, A. 2017. Random User Generator. Available: https://randomuser.me/ [Accessed 8 Jan 2018].

ASSUNÇÃO, M. D., CALHEIROS, R. N., BIANCHI, S., NETTO, M. A. \& BUYYA, R. 2015. Big Data computing and clouds: Trends and future directions. Journal of Parallel and Distributed Computing, 79, 3-15.

BAEHRENS, D., SCHROETER, T., HARMELING, S., KAWANABE, M., HANSEN, K. \& MÃŽLLER, K.-R. 2010. How to explain individual classification decisions. Journal of Machine Learning Research, 11, 1803-1831.

BEILLEV AIRE, M. 2016. Inside the Black Box: How to Explain Individual Predictions of a Machine Learning Model.

BELLINGER, C., SHARMA, S. \& JAPKOWICZ, N. One-class versus binary classification: Which and when? Machine Learning and Applications (ICMLA), 2012 11th International Conference on, 2012. IEEE, 102-106.

BENEVENUTO, F., MAGNO, G., RODRIGUES, T. \& ALMEIDA, V. Detecting spammers on twitter. Collaboration, electronic messaging, anti-abuse and spam conference (CEAS), 2010. 12.

BIAU, G. 2012. Analysis of a random forests model. Journal of Machine Learning Research, 13, 1063-1095.

BLISS, L. 2017. The Law, Social Media and the Victimisation of Women. Socio-Legal Studies Association Annual Conference. Newcastle University.

BOGDANOVA, D., ROSSO, P. \& SOLORIO, T. 2014. Exploring high-level features for detecting cyberpedophilia. Computer Speech \& Language, 28, 108-120.

BREIMAN, L. 2001. Random forests. Machine learning, 45, 5-32.
BURRELL, J. 2016. How the machine 'thinks': Understanding opacity in machine learning algorithms. Big Data \& Society, 3, 2053951715622512.

CAMBER, R. 2014. Oil millionaire's son, 14, 'found murdered in flat 30 miles from home after being groomed through computer games': Man, 18, charged after stabbing. Available: http://www.dailymail.co.uk/news/article2562890/BREAKING-NEWS-Son-14-oil-millionairemurdered-man-groomed-computer-games.html [Accessed 8 Jan 2018].

CASPI, A. \& GORSKY, P. 2006. Online deception: Prevalence, motivation, and emotion. CyberPsychology \& Behavior, 9, 54-59.

CHAFFEY, D. 2016. Global social media research summary 2016. Smart Insights: Social Media Marketing.

CHOUDHARY, N. \& JAIN, A. K. 2017. Towards Filtering of SMS Spam Messages Using Machine Learning Based Technique. Advanced Informatics for Computing Research. Springer, Singapore.

CHU, Z., GIANVECCHIO, S., WANG, H. \& JAJODIA, S. Who is tweeting on Twitter: human, bot, or cyborg? Proceedings of the 26th annual computer security applications conference, 2010. ACM, 21-30.

COOK, D. M. 2014. Birds of a Feather Deceive Together: The Chicanery of Multiplied Metadata. Journal of Information Warfare, 13, 85-96.

CRESCI, S., DI PIETRO, R., PETROCCHI, M., SPOGNARDI, A. \& TESCONI, M. 2015. Fame for sale: efficient detection of fake Twitter followers. Decision Support Systems, 80, 56-71.

DAL POZZOLO, A., CAELEN, O., WATERSCHOOT, S. \& BONTEMPI, G. Racing for unbalanced methods selection. International Conference on Intelligent Data Engineering and Automated Learning, 2013. Springer, 24-31.

DE VILLIERS, J. 2017. Suspects use fake Facebook profile to lure women, rape and kill them. News24 [Online]. Available: https://www.news24.com/SouthAfrica/News/suspects-usefake-facebook-profile-to-lure-women-rape-and-kill-them20171104 [Accessed 4 Nov 2017].

DEPAULO, B. M., KASHY, D. A., KIRKENDOL, S. E., WYER, M. M. \& EPSTEIN, J. A. 1996. Lying in everyday life. Journal of personality and social psychology, 70, 979.

DICKERSON, J. P., KAGAN, V. \& SUBRAHMANIAN, V. Using sentiment to detect bots on Twitter: Are humans more opinionated than bots? Advances in Social Networks Analysis and Mining (ASONAM), 2014 IEEE/ACM International Conference on, 2014. IEEE, 620-627.

DIGITAL, T. 2016. Mbete doesn't recognise these tweets - speaker spoofed on Twitter. Times Live [Online]. Available: http://www.timeslive.co.za/politics/2016/04/13/Mbetedoesnt-recognise-these-tweets---speaker-spoofed-on-Twitter [Accessed 13 April 2016].

DROUIN, M., MILLER, D., WEHLE, S. M. \& HERNANDEZ, E. 2016. Why do people lie online? "Because everyone lies on the internet". Computers in Human Behavior, 64, 134-142.

EBRAHIMI, M., SUEN, C. Y., ORMANDJIEVA, O. \& KRZYZAK, A. 2016. Recognizing Predatory Chat Documents using Semi-supervised Anomaly Detection. Electronic Imaging, 2016, 1-9.

FACEBOOK. 2017. The Facebook Graph API. Available: https://developers.facebook.com/docs/graph-api/overview [Accessed 8 Jan 2018].

FERRARA, E., WANG, W.-Q., VAROL, O., FLAMMINI, A. \& GALSTYAN, A. Predicting online extremism, content adopters, and interaction reciprocity. International Conference on Social Informatics, 2016. Springer, 22-39.

FIRE, M., KAGAN, D., ELYASHAR, A. \& ELOVICI, Y. 2014. Friend or foe? Fake profile identification in online social networks. Social Network Analysis and Mining, 4, 1-23. 
GALÁN-GARCÍA, P., DE LA PUERTA, J. G., GÓMEZ, C. L., SANTOS, I. \& BRINGAS, P. G. 2015. Supervised machine learning for the detection of troll profiles in twitter social network: Application to a real case of cyberbullying. Logic Journal of IGPL, jzv048.

GENUER, R., POGGI, J.-M. \& TULEAU-MALOT, C. 2010. Variable selection using random forests. Pattern Recognition Letters, 31, 2225-2236.

GOODMAN, B. \& FLAXMAN, S. 2016. European Union regulations on algorithmic decision-making and a" right to explanation". arXiv preprint arXiv: 1606.08813.

GOOGLE. 2017. Google Vision API. Available: https://cloud.google.com/vision/ [Accessed 8 Jan 2018].

GOOGLE+. 2017. Google+ API. Available: https://developers.google.com/+/web/api/rest/ [Accessed 8 Jan 2018].

GU, G., PERDISCI, R., ZHANG, J. \& LEE, W. BotMiner: Clustering Analysis of Network Traffic for Protocol-and StructureIndependent Botnet Detection. USENIX security symposium, 2008. 139-154.

GURAJALA, S., WHITE, J. S., HUDSON, B. \& MATTHEWS, J. N. Fake Twitter accounts: profile characteristics obtained using an activity-based pattern detection approach. Proceedings of the 2015 International Conference on Social Media \& Society, 2015. ACM, 9.

GURAJALA, S., WHITE, J. S., HUDSON, B., VOTER, B. R. \& MATTHEWS, J. N. 2016. Profile characteristics of fake Twitter accounts. Big Data \& Society, 3, 2053951716674236.

HAIMSON, O. L. \& HOFFMANN, A. L. 2016. Constructing and enforcing" authentic" identity online: Facebook, real names, and non-normative identities. First Monday, 21.

HALEVY, R., SHALVI, S. \& VERSCHUERE, B. 2014. Being honest about dishonesty: Correlating self- reports and actual lying. Human Communication Research, 40, 54-72.

HANCOCK, J. T. 2007. Digital deception, Oxford University Press.

HANCOCK, J. T. \& TOMA, C. L. 2009. Putting your best face forward: The accuracy of online dating photographs. Journal of Communication, 59, 367-386.

INSTAGRAM. 2017. Instagram API. Available: https://www.instagram.com/developer/ [Accessed 8 Jan 2018].

JENI, L. A., COHN, J. F. \& DE LA TORRE, F. Facing imbalanced data--Recommendations for the use of performance metrics. Affective Computing and Intelligent Interaction (ACII), 2013 Humaine Association Conference on, 2013. IEEE, 245251.

JUPE, L. M., VRIJ, A., NAHARI, G., LEAL, S. \& MANN, S. A. 2016. The lies we live: Using the verifiability approach to detect lying about occupation. Journal of Articles in Support of the Null Hypothesis, 13, 1-13.

KABAY, M., SALVEGGIO, E., GUESS, R. \& ROSCO, R. D. 2014. Anonymity and Identity in Cyberspace. Computer Security Handbook, Sixth Edition, 70.1-70.37.

KEEN, B. 2017. Generate Data. Available: http://www.generatedata.com/ [Accessed 8 Jan 2018].

KHANDPUR, R. P., JI, T., JAN, S., WANG, G., LU, C.-T. \& RAMAKRISHNAN, N. 2017. Crowdsourcing Cybersecurity: Cyber Attack Detection using Social Media. arXiv preprint arXiv: 1702.07745 .

KIERKEGAARD, S. 2008. Cybering, online grooming and ageplay. Computer Law \& Security Review, 24, 41-55.

KLAUSEN, J. 2015. Tweeting the jihad: Social media networks of Western foreign fighters in Syria and Iraq. Studies in Conflict \& Terrorism, 38, 1-22.

KOTHARI, C. R. 2004. Research methodology: Methods and techniques, New Age International.

KUHN , M., WESTON, S., WILLIAMS, A., KEEFER, C., ENGELHARDT, A., COOPER, T., MAYER, Z. \& AL., E.
2016. caret: Classification and regression training. $\mathrm{R}$ package version 6.0-73.

LEVENSHTEIN, V. I. Binary codes capable of correcting deletions, insertions, and reversals. Soviet physics doklady, 1966. 707710

LI, J. \& WANG, A. G. 2015. A framework of identity resolution: evaluating identity attributes and matching algorithms. Security Informatics, 4, 1.

LINKEDIN. 2017. LinkedIn Developers. Available: https://developer.linkedin.com/ [Accessed 8 Jan 2018].

LIPTON, Z. C. 2016. The mythos of model interpretability. arXiv preprint arXiv: 1606.03490 .

MA, C., ZHANG, H. H. \& WANG, X. 2014. Machine learning for Big Data analytics in plants. Trends in plant science, 19, 798808

MANN, H. B. \& WHITNEY, D. R. 1947. On a test of whether one of two random variables is stochastically larger than the other. The annals of mathematical statistics, 50-60.

MCDONALD, J. H. 2009. Handbook of biological statistics, Sparky House Publishing Baltimore, MD.

MENARDI, G. \& TORELLI, N. 2014. Training and assessing classification rules with imbalanced data. Data Mining and Knowledge Discovery, 1-31.

OENTARYO, R. J., MURDOPO, A., PRASETYO, P. K. \& LIM, E.P. On Profiling Bots in Social Media. International Conference on Social Informatics, 2016. Springer, 92-109.

PEDDINTI, S. T., ROSS, K. W. \& CAPPOS, J. 2017. Mining Anonymity: Identifying Sensitive Accounts on Twitter. arXiv preprint arXiv: 1702.00164.

PETERSON, T. 2016. Rapist who used social media to lure child victims sentenced to 20 years. News24, 15 Jun 2016.

PINTEREST. 2017. Pinterest API. Available: https://developers.pinterest.com/ [Accessed 8 Jan 2018].

RÉNYI, A. On measures of entropy and information. Proceedings of the fourth Berkeley symposium on mathematical statistics and probability, 1961. 547-561.

RIBEIRO, M. T., SINGH, S. \& GUESTRIN, C. Why should i trust you?: Explaining the predictions of any classifier. Proceedings of the 22nd ACM SIGKDD International Conference on Knowledge Discovery and Data Mining, 2016. ACM, 1135-1144.

RONG, R., HOUSER, D. \& DAI, A. Y. 2016. Money or friends: Social identity and deception in networks. European Economic Review, 90, 56-66.

RUBIN, V. L. 2017. Deception Detection and Rumor Debunking for Social Media. The SAGE Handbook of Social Media Research Methods, 342.

SAABAS, A. 2018. Contribute to treeinterpreter development by creating an account on GitHub.

SCHWARTZ, H. A., EICHSTAEDT, J. C., KERN, M. L., DZIURZYNSKI, L., RAMONES, S. M., AGRAWAL, M., SHAH, A., KOSINSKI, M., STILLWELL, D. \& SELIGMAN, M. E. 2013. Personality, gender, and age in the language of social media: The open-vocabulary approach. PloS one, 8, e73791.

SEDHAI, S. \& SUN, A. 2017. Semi-Supervised Spam Detection in Twitter Stream. arXiv preprint arXiv:1702.01032.

SHANNON, C. E. 2001. A mathematical theory of communication. ACM SIGMOBILE Mobile Computing and Communications Review, 5, 3-55.

SHAPLEY, L. S. 1953. A value for n-person games. Contributions to the Theory of Games, 2, 307-317.

SHUMAKER, B. \& SINNOTT, R. 1984. Astronomical computing: 1. Computing under the open sky. 2. Virtues of the haversine. Sky and telescope, 68, 158-159.

SMIT, D. 2015. Cyberbullying in South African and American schools: A legal comparative study. South African Journal of Education, 35, 01-11. 
STANTON, K., ELLICKSON-LAREW, S. \& WATSON, D. 2016.

Development and validation of a measure of online deception and intimacy. Personality and Individual Differences, 88, 187-196.

THOMAS, K., GRIER, C., SONG, D. \& PAXSON, V. Suspended accounts in retrospect: an analysis of twitter spam. Proceedings of the 2011 ACM SIGCOMM conference on Internet measurement conference, 2011. ACM, 243-258.

TOMA, C. L., HANCOCK, J. T. \& ELLISON, N. B. 2008. Separating fact from fiction: An examination of deceptive selfpresentation in online dating profiles. Personality and Social Psychology Bulletin, 34, 1023-1036.

TSIKERDEKIS, M. 2017. Identity Deception Prevention Using Common Contribution Network Data. IEEE Transactions on Information Forensics and Security, 12, 188-199.

TSIKERDEKIS, M. \& ZEADALLY, S. 2014. Multiple Account Identity Deception Detection in Social Media Using Nonverbal Behavior. Information Forensics and Security, IEEE Transactions on, 9, 1311-1321.

TUNA, T., AKBAS, E., AKSOY, A., CANBAZ, M. A. KARABIYIK, U., GONEN, B. \& AYGUN, R. 2016. User characterization for online social networks. Social Network Analysis and Mining, 6, 104

TUTEJA, S. K. 2016. A Survey on Classification Algorithms for Email Spam Filtering. International Journal of Engineering Science, 5937.

TWITTER. 2017. Twitter API. Available: https://dev.twitter.com/overview/api [Accessed 8 Jan 2018].

UTZ, S. 2005. Types of deception and underlying motivation: What people think. Social Science Computer Review, 23, 49-56.

VAN DER WALT, E. \& ELOFF, J. H. P. 2018. Using Machine Learning to Detect Fake Identities - Bots versus Humans. IEEE Access, Currently under review.

VAN LIERE, D. How far does a tweet travel?: Information brokers in the twitterverse. Proceedings of the International Workshop on Modeling Social Media, 2010. ACM, 6.

VENKATESAN, S., ALBANESE, M., SHAH, A., GANESAN, R. \& JAJODIA, S. 2017. Detecting Stealthy Botnets in a Resource-Constrained Environment using Reinforcement Learning.

WANG, G. A., CHEN, H., XU, J. J. \& ATABAKHSH, H. 2006. Automatically detecting criminal identity deception: an adaptive detection algorithm. Systems, Man and Cybernetics, Part A: Systems and Humans, IEEE Transactions on, 36 , 988-999.

WOLPERT, D. H. \& MACREADY, W. G. 1997. No free lunch theorems for optimization. IEEE transactions on evolutionary computation, 1, 67-82.

YARKONI, T. \& WESTFALL, J. 2016. Choosing prediction over explanation in psychology: Lessons from machine learning. Unpublished manuscript.

ZAFARANI, R. \& LIU, H. 2015. Evaluation without ground truth in social media research. Communications of the ACM, 58, 5460. 


\section{APPENDIX A}

\begin{tabular}{|c|c|c|c|c|c|c|c|}
\hline \multirow[b]{2}{*}{ Attribute Group } & \multirow[b]{2}{*}{ General Attribute Description } & \multicolumn{6}{|c|}{ Social media attributes } \\
\hline & & (Facebook, 2017) & $($ Google,+ 2017$)$ & \begin{tabular}{|l|} 
(LinkedIn, \\
2017)
\end{tabular} & (Twitter, 2017) & $\begin{array}{l}\text { (Pinterest, } \\
\text { 2017) }\end{array}$ & (Instagram, 2017) \\
\hline Profile information & $\begin{array}{l}\text { The ID of the person's user account } \\
\text { Their first name } \\
\text { Their last name } \\
\text { Middle name } \\
\text { Full name } \\
\text { Name to display } \\
\text { Age } \\
\text { Birth date } \\
\text { Profile picture } \\
\text { Background picture } \\
\text { Email/Phone } \\
\text { Gender } \\
\text { Relationship status } \\
\text { Language } \\
\text { Location } \\
\text { Geolocation } \\
\text { Timezone } \\
\text { UTC offset } \\
\text { Bio field }\end{array}$ & $\begin{array}{l}\text { ID } \\
\text { first_name } \\
\text { last_name } \\
\text { middle_name } \\
\text { name } \\
\text { age_range } \\
\text { birthday } \\
\text { cover } \\
\text { email/phone } \\
\text { gender } \\
\text { relationship_status } \\
\text { languages } \\
\text { location } \\
\text { timezone } \\
\text { about }\end{array}$ & $\begin{array}{l}\text { ID } \\
\text { name.givenName } \\
\text { name.familyName } \\
\text { name.middleName } \\
\text { name.formatted } \\
\text { displayName } \\
\text { ageRange } \\
\text { birthday } \\
\text { image } \\
\text { emails[] } \\
\text { gender } \\
\text { relationshipStatus } \\
\text { language } \\
\text { placesLived[].primary } \\
\\
\\
\text { aboutMe }\end{array}$ & $\begin{array}{l}\text { formatted-name } \\
\text { date-of-birth } \\
\text { picture-url } \\
\text { email-address } \\
\text { languages } \\
\text { location } \\
\text { summary }\end{array}$ & $\begin{array}{l}\text { ID } \\
\text { name } \\
\text { screen_name } \\
\text { profile_image } \\
\text { background_image } \\
\text { email/phone } \\
\\
\text { lang } \\
\text { location } \\
\text { geo-enabled, } \\
\text { latitude, longitude } \\
\text { time_zone } \\
\text { utc_offset } \\
\text { description }\end{array}$ & $\begin{array}{l}\text { username } \\
\text { image } \\
\text { email }\end{array}$ & $\begin{array}{l}\text { full_name } \\
\text { Username } \\
\text { profile_picture } \\
\text { email/phone }\end{array}$ \\
\hline Account information & $\begin{array}{l}\text { Authenticity of account } \\
\text { Updated time }\end{array}$ & $\begin{array}{l}\text { is_verified } \\
\text { updated_time }\end{array}$ & verified & & $\begin{array}{l}\text { verified } \\
\text { created_at } \\
\text { protected }\end{array}$ & & \\
\hline Behaviour & $\begin{array}{l}\text { List of devices } \\
\text { Likes }\end{array}$ & $\begin{array}{l}\text { devices } \\
\text { likes }\end{array}$ & & & statuses_count & & media.likes \\
\hline Relationships & $\begin{array}{l}\text { Friends } \\
\text { Groups } \\
\text { Listed } \\
\text { Family }\end{array}$ & $\begin{array}{l}\text { friends } \\
\text { groups }\end{array}$ & & $\begin{array}{l}\text { num-connections } \\
\text { following } \\
\text { job-bookmarks }\end{array}$ & $\begin{array}{l}\text { followers_count } \\
\text { friends_count } \\
\text { listed_count }\end{array}$ & & \\
\hline
\end{tabular}




\begin{tabular}{|c|c|c|c|c|c|c|c|}
\hline \multirow[b]{2}{*}{ Attribute Group } & \multirow[b]{2}{*}{ General Attribute Description } & \multicolumn{6}{|c|}{ Social media attributes (continued) } \\
\hline & & (Facebook, 2017) & (Google+, 2017) & \begin{tabular}{|l} 
(LinkedIn, \\
2017)
\end{tabular} & (Twitter, 2017) & \begin{tabular}{|l} 
(Pinterest, \\
2017)
\end{tabular} & (Instagram, 2017) \\
\hline Content & $\begin{array}{l}\text { Recommendations } \\
\text { Content specific fields }\end{array}$ & \begin{tabular}{|l} 
albums \\
feeds \\
events \\
photos \\
videos
\end{tabular} & $\begin{array}{l}\text { curls[] } \\
\text { organizations[] } \\
\text { braggingRights } \\
\text { occupation } \\
\text { skills }\end{array}$ & \begin{tabular}{|l} 
num- \\
recommenders \\
position \\
Skills \\
certifications \\
educations \\
courses \\
volunteer \\
publications \\
interests \\
honors-awards
\end{tabular} & $\begin{array}{l}\text { user_mentions } \\
\text { tweets } \\
\text { tweets.created_at }\end{array}$ & $\begin{array}{l}\text { counts } \\
\text { boards } \\
\text { pins }\end{array}$ & $\begin{array}{l}\text { Counts } \\
\text { Media } \\
\text { media.created_time } \\
\text { media.location }\end{array}$ \\
\hline
\end{tabular}

Note: Sources are shown in square brackets under the relevant SMP.

A.1 Social media attributes as identified in for the top 6 SMPs of 2016 


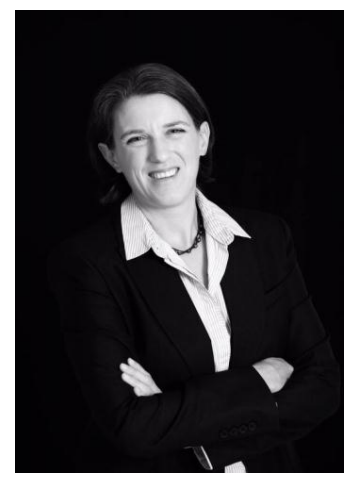

Estée van der Walt was born in Johannesburg, South Africa in 1977. She received B.Sc. and M.Sc. degrees in Computer Science from the University of Johannesburg, South Africa, in 1997 and 2001 respectively. She is currently completing her Ph.D. degree in Information Technology at the University of Pretoria, South Africa.

Her research interests include cyber-security and identity deception on social media platforms. She is particularly interested in the protection of humans on these big data platforms. She makes use of machine learning and data mining techniques to not only understand this type of deception but also find a solution to detect and warn authorities about identity deception.

She was the recipient of the "Best Poster Award" at the 3rd International Conference on Information Systems Security and Privacy that was hosted in Porto, Portugal during February 2017.

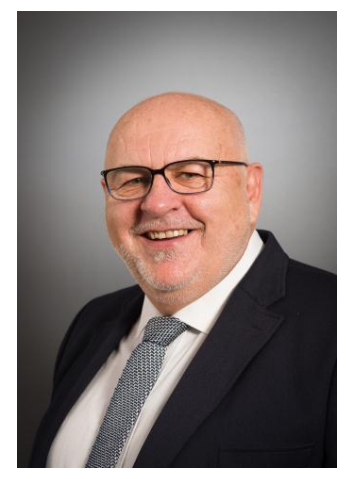

Jan Eloff graduated in 1985 with a Ph.D. in Computer Science. Up to June 2015 he was appointed as the Research Director for SAP Research in Africa and is currently appointed as Deputy Dean Research \& Postgraduate studies: Faculty of Engineering, Built Environment and IT (EBIT), and as a full professor in computer science at the University of Pretoria, South Africa. From 2007 he is an associate-editor of the Computers \& Security journal and an editorial member for the International Computer Fraud \& Security bulletin published by Elsevier. He is an internationally 
recognised researcher and has published 113 peer reviewed papers with 3537 citations.

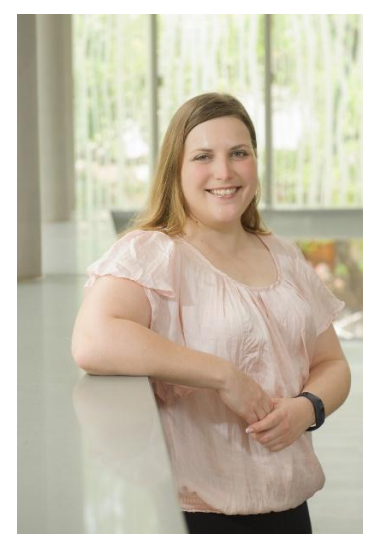

Jacomine Grobler is a senior lecturer in the Department of Industrial and Systems Engineering at the University of Pretoria in South Africa. Her main fields of expertise are multi-method optimization algorithms, swarm intelligence, multi-objective optimization, supply chain optimization and big data science. She completed her PhD in 2014 and was recently awarded the 2015 JD Roberts emerging researcher award for her contribution to the development of mathematical models and optimization algorithms. She also received the 2017 South African Institute for Industrial Engineering Most Outstanding Young Industrial Engineering Researcher Award. She regularly reviews papers for leading international journals and have presented various invited lectures, for example, a tutorial at the Seventh International Conference on Swarm Intelligence in Bali, Indonesia. 